\title{
Diet quality is associated with malnutrition and low calf circumference in Canadian long-term care residents
}

\author{
Natalie Carrier ${ }^{1 *} \mathbb{D}$, Lita Villalon', Christina Lengyel ${ }^{2}$, Susan E. Slaughter ${ }^{3}$, Lisa Duizer ${ }^{4}$, Jill Morrison-Koechl ${ }^{6}$ and
} Heather Keller ${ }^{5}$

\begin{abstract}
Background: Older adults living in long-term care (LTC) are nutritionally vulnerable. The purpose of this study was to determine diet quality of Canadian LTC residents and its association with malnutrition and low calf circumference.

Methods: A cross-sectional study was undertaken in 32 LTC homes across four Canadian provinces. Nutrient adequacy ratios (NARs) were calculated for seventeen nutrients; mean adequacy ratio (MAR) was calculated to describe overall diet quality. Malnutrition risk was assessed with the Mini Nutritional Assessment-Short Form (MNASF) and diagnosis of protein/energy malnutrition with the Patient-Generated Subjective Global Assessment (PGSGA). Calf circumference (CC) was also assessed. Linear and logistic regressions for these outcomes with diet quality as the predictor were conducted adjusting for covariates.
\end{abstract}

Results: Average MNA-SF score was $10.7 \pm 2.5$. Residents (43.5\%) had mild/moderate to severe malnutrition based on the PG-SGA and $32.6 \%$ had a CC of $<31 \mathrm{~cm}$. Mean MAR score was $0.79 \pm 0.09$ with significant differences between those requiring eating assistance $(0.77 \pm 0.11)$ and those that did not require assistance $(0.80 \pm 0.07)$ $(p<.05)$. MAR score was significantly associated with malnutrition in fully adjusted models: MNA-SF scores $[\beta=5.34$, 95\% Confidence interval $(\mathrm{Cl})(2.81,7.85)]$ and PG-SGA [Odds ratio $(\mathrm{OR})=0.49,95 \% \mathrm{Cl}(0.38,0.64)]$. Those who had better diet quality were more likely to be well nourished or not at risk. Although several individual nutrients were associated with low CC $(<31 \mathrm{~cm})$, there was no association between overall diet quality (MAR) and low CC.

Conclusions: Diet quality is associated with malnutrition and individual nutrients (NARs) with a low CC. In addition to calories and protein, nutrient dense diets that promote adequate micronutrient intake are required in LTC.

Keywords: Diet quality, Long-term care, Malnutrition, Calf circumference, Eating assistance

\section{Background}

Older adults living in long-term care (LTC) facilities are nutritionally vulnerable [1-3]. Poor food and fluid intake, resulting from multifactorial challenges such as dysphagia, is a primary cause for malnutrition in this setting [4]. Residents' average energy intake is estimated at $1500 \mathrm{kcal} /$ day or less [4-6]. With low energy intake, it is not surprising that up to $70 \%$ of residents have lower than

\footnotetext{
* Correspondence: natalie.carrier@umoncton.ca

${ }^{1}$ École des sciences des aliments, de nutrition et d'études familiales, Faculté des sciences de la santé et des services communautaires, Université de Moncton, Moncton, NB E1A 3E9, Canada

Full list of author information is available at the end of the article
}

recommended intakes of many micronutrients $[4,5,7]$. Diet quality is defined in this study as meeting protein and micronutrient requirements relative to the Recommended Dietary Allowance of the Dietary Reference Intakes. Identifying what specific nutrients are lacking in the diet is worthwhile as potential targets for intervention. It is anticipated that many of the sequelae of protein/energy malnutrition are also associated with specific micronutrient deficiencies and overall diet quality. A first step is to determine micronutrient inadequacies associated with protein/energy malnutrition.

Calf circumference (CC) is a simple tool that can be used as a surrogate indicator of muscle mass and as

(c) The Author(s). 2019 Open Access This article is distributed under the terms of the Creative Commons Attribution 4.0 International License (http://creativecommons.org/licenses/by/4.0/), which permits unrestricted use, distribution, and reproduction in any medium, provided you give appropriate credit to the original author(s) and the source, provide a link to the Creative Commons license, and indicate if changes were made. The Creative Commons Public Domain Dedication waiver (http://creativecommons.org/publicdomain/zero/1.0/) applies to the data made available in this article, unless otherwise stated. 
some have suggested, sarcopenia [8, 9]. A CC of $<31 \mathrm{~cm}$ indicates a risk of sarcopenia and frailty [10, 11]. To date, some studies have determined an association between vitamin $\mathrm{D}$ and loss of muscle function and strength in older adults [12-15], yet few studies have examined the associations between other micronutrients and muscle mass or low $\mathrm{CC}$ in this population.

Without careful menu planning and the use of standardized recipes and portion sizes, diet quality of menus can be poor [16]. Modified texture menus, especially those for pureed consumers, are typically lower in energy and micronutrients than regular menus [16-18]. Diet quality may also be further exacerbated for specific residents in LTC. For example, persons with dementia often require physical assistance with eating to improve their food and fluid intake [19-21]. Residents who lose the ability to eat are at a greater risk for malnutrition [22-24] and oral nutritional supplements (ONS) are often used to treat malnutrition [5, 24]. According to Simmons et al. (2010), offering residents a variety of foods and fluids in between meals may be a more effective way of improving nutritional status [25]. In the Making the Most of Mealtimes (M3) data set, we have demonstrated that about a third of micronutrients analyzed had high proportions $(>50 \%)$ of participants consuming levels below the recommendations [26]. However, limited research has explored the association between intake of specific nutrients or diet quality with malnutrition or low CC in LTC residents. This cross-sectional, multi-site study aimed to determine nutrient and overall diet quality of LTC residents and its association with malnutrition and low CC.

\section{Methods}

\section{Study design and setting}

This cross-sectional study was undertaken in 32 LTC homes across four Canadian provinces: Alberta, Manitoba, New Brunswick and Ontario and conducted between October 2014 and March 2016. The main study questions regarding determinants of food intake and prevalence of inadequate intake were used to determine the sample size. In brief, a convenience sample of homes was recruited in each province to promote diversity (e.g., profit structure, corporate vs. independent homes, ethnic focus, size). Home eligibility criteria included: being in operation for at least six months; and having a minimum of 50 residents who met the resident eligibility criteria. One to four units in each home were randomly selected for recruitment of participants; if the home had a dementia care unit, this was included.

\section{Participants}

Residents were randomly selected and recruited to reach a quota of 20 residents per home. Participant inclusion criteria were: $65+$ years of age; not palliative and medically stable (no hospital admission in previous month); not recently or temporarily admitted to the home; not requiring tube feeding or end of life care; and mostly eating in the dining room. Informed written consent was provided by the resident or their alternate decisionmaker. The resident sample size per province $(n=160)$ and for the entire study $(n=640)$ was based on the analyses planned for the main study (multi-level regression modeling) [27], which allowed identification of the independent determinants of inadequate food intake. One participant revoked their consent to participate after data were collected, bringing the total sample to 639 participants. Of these, only 619 participants had complete data on all variables of interest for this paper.

\section{Data collection tools and procedures}

Four trained (dietetic program prepared or dietitian) research coordinators collected health and nutritional status data. Details on all data collected can be found in the protocol paper [27] and only those variables used in this analysis will be described. Resident data, such as diagnosis, prescription of ONS, and dietary prescription were collected from health charts. In addition, modified texture diets (MTD) were classified for analysis using the International Dysphagia Diet Standardisation Initiative (IDDSI) $[16,28]$ as more than 60 diet textures were represented in the data. Specifically, five categories of the IDDSI continuum were used to categorize food texture $(3=$ liquidized, $4=$ pureed, $5=$ minced and moist, $6=$ soft and bite-sized, and $7=$ regular texture). Modified texture diets were dichotomized as either yes or no; "yes" representing categories 3,4 and 5 of the IDDSI and "no" representing categories 6 and 7. Activities of daily living and cognitive performance were collected using the interRAI-LTCF 2.0 [27-29]. The interRAILTCF provides a standardized and validated means of collecting comprehensive clinical information on LTC residents [29]. Residents' CC was measured using standardized procedures [30]. Health record information and discussion with staff, family and/or the resident were used to complete the Mini Nutritional Assessment-Short Form (MNA-SF) [31] and the resident was examined to complete the Patient-Generated Subjective Global Assessment (PG-SGA) [32]. The MNA-SF scores were continuous, ranging from 0 to 14 , where higher scores indicated better nutritional status and a cut-point of $<12$ indicated malnutrition risk. The PG-SGA ratings of A (well nourished), B (mild/moderate malnutrition) and C (severe malnutrition) were used; the numerical score was not used as it has not been validated for this population [27]. The PG-SGA ratings were dichotomized such that mild/moderate and severe malnutrition were combined $(\mathrm{B} / \mathrm{C})$ for this analysis. 


\section{Dietary assessment}

Two trained research assistants per province collected meal-level data for each participant. Researchers completed a standardized form three times (once per day of food intake data collection) to identify eating behaviours and mealtime experiences of participants. Physical assistance with eating was determined by observation using a single item from the validated Edinburgh Feeding Evaluation in Dementia Questionnaire (Ed-FED-Q) and nine additional eating challenges (e.g., does the resident get distracted, do they cough during the meal, choke etc.) were also recorded and scaled to be consistent with Ed-FED-Q (never (1), sometimes (2), frequent (3)) [33]. The rounded average of these three mealtime observations were used and residents categorized as no physical assistance vs. requiring physical assistance. Three non-consecutive days (two weekdays and one weekend day) of weighed food intake (before and after consumption of main plates), with estimated beverages, side dishes and snacks, were collected for each resident. Nutritional analysis software (ESHA Food Processor, version 10.14.1), with the Canadian Nutrient File, was used to obtain mean daily intake of energy (kcal), protein (g), and several micronutrients. Oral nutritional supplements to promote energy and protein intake either at meals, snacks or medical rounds were included in this analysis. Micronutrient supplement use was not included in this analysis; consumption of vitamins and minerals is based on intake of food, beverages and any ONS. For this study, diet quality was determined by nutrient adequacy ratios (NARs) for seventeen nutrients (calcium, copper, folate, iron, magnesium, phosphorus, selenium, vitamins $A, B_{1}, B_{2}$, $\mathrm{B}_{3}, \mathrm{~B}_{6}, \mathrm{~B}_{12}, \mathrm{C}, \mathrm{D}, \mathrm{E}$ [ $\alpha$-tocopherol], zinc) and a mean adequacy ratio (MAR), which was the average of the seventeen NARs. NARs were calculated as the proportion consumed relative to the corresponding sex and age-specific. Recommended Dietary Allowance for each nutrient; a maximum of 1.0 indicated that the recommendation was met/exceeded [34] and a MAR score closer to 1.0 indicated better overall diet quality. All data were collected on paper forms and transferred to RedCAP (Vanderbilt University) for transfer to the research centre for analysis.

\section{Statistical analyses}

Descriptive statistics (mean, median, frequency) of resident characteristics were computed. The associations of each diet parameter (i.e., energy and protein intake, MAR, NARs) with nutritional risk, malnutrition and low CC, were tested. Models were adjusted for age and sex as these demographic variables drive food intake. Hierarchical regression analysis accounted for clustering at the home and unit levels; linear regression tested the association with MNA-SF score while logistic regression estimated the odds ratios for PG-SGA risk and low CC. In addition to the simple models adjusted for age and sex, fully adjusted models also included three residentlevel covariates (i.e., MTD (IDDSI categories 3-5), ONS use, requiring physical assistance (sometimes or often)) that are prevalent in this sample and demonstrated to be associated with malnutrition [5, 16-25]. Statistical significance was set at $p<0.05$. All analyses were performed using SAS/STAT ${ }^{\circ}$ 9.4 statistical software (SAS Institute Inc., Cary, North Carolina). This study was approved by the research ethics boards at the University of Waterloo (ORE\#20056), University of Alberta (Pro00050002), University of Manitoba (J2014:139), and Université de Moncton (1415-022) and complies with the current laws of Canada.

\section{Results}

The sample is described in Table 1. Average age of participants was $86.8 \pm 7.8$ years, $31.2 \%$ were men, and $55.5 \%$ had moderate to severe cognitive impairment. Almost a quarter of participants required eating assistance, one-third were on MTD, and one-third were prescribed ONS. Mean CC was $33.3 \pm 4.8$ with $32.6 \%$ having a CC of $<31 \mathrm{~cm}$. Mean MNA-SF score was $10.7 \pm 2.5$, with $53.3 \%$ below the malnutrition risk cut-point $(<12)$ while 43.5\% were classified as malnourished with PG-SGA.

Residents' food intake and diet quality by MTD use, ONS prescription and physical assistance with eating are provided in Table 2. Participants' mean adjusted energy intake was $1556.3 \pm 294.1 \mathrm{kcal} /$ day and protein intake was $57.5 \pm 13.0 \mathrm{~g} /$ day. Almost two-thirds of participants were meeting the required daily intake of protein using the 0.8 $\mathrm{g} / \mathrm{kg}$ body weight/day cut-point. Participants using MTD or ONS or those that required any physical assistance with eating had significantly lower energy intake than those on regular texture diets, not prescribed ONS or not requiring assistance with eating. Protein intake was only significantly lower in participants requiring assistance with eating as compared to those not requiring any eating assistance $(54.9 \pm 14.7$ vs. $58.4 \pm 12.2)$. Mean MAR score (diet quality) for the total sample was $0.79 \pm 0.09$ with those requiring assistance with eating having significantly lower scores than participants not requiring physical assistance with eating. No significant difference in MAR were observed between participants on regular texture diets and those on MTD and between participants prescribed ONS and those that were not. For the total sample, the mean NAR scores were greater than 0.70 for the majority of the 17 nutrients (maximum of 1.0 indicating that Recommended Dietary Allowance for the nutrient was met or exceeded) except for the following five nutrients, which had much lower NAR scores: vitamin D (0.28), vitamin E (0.34), folate (0.58), calcium (0.61) and magnesium (0.65). Individual NAR scores for most nutrients were consistently lower in participants on MTD, ONS, and requiring 
Table 1 Sample characteristic and outcomes of interest

\begin{tabular}{|c|c|}
\hline Resident Characteristics & Mean (SD) \\
\hline Age, years & $86.8(7.8)$ \\
\hline Sex, male (\%) & 31.2 \\
\hline Moderate/severe cognitive impairment, (CPS score $\geq 3$ ), yes (\%) & 55.5 \\
\hline Ed-FED-Q Score ${ }^{a}$ & $12.4(2.3)$ \\
\hline Other eating behaviors Score $(\text { maximum }=27)^{a}$ & $10.6(1.6)$ \\
\hline Activity of daily living Scale ${ }^{a}$ & $15.0(7.8)$ \\
\hline Physical assistance (sometimes or often) with eating required ${ }^{\mathrm{a}}(\%)$ & 22.9 \\
\hline Total number of diagnoses & $5.4(2.0)$ \\
\hline Any ONS prescribed, yes (\%) & 30.5 \\
\hline MTD (IDDSI category 3-5), yes (\%) & 33.0 \\
\hline \multicolumn{2}{|l|}{ Outcome variables } \\
\hline $\mathrm{CC}, \mathrm{cm}$ & $33.3(4.8)$ \\
\hline $\mathrm{CC}<31 \mathrm{~cm}^{\mathrm{b}}(\%)$ & 32.6 \\
\hline MNA-SF & $10.7(2.5)$ \\
\hline Malnourished/At risk of malnutrition (MNA-SF < 12) $(\%)$ & 53.3 \\
\hline PG-SGA (Malnutrition = B/C) (\%) & 43.5 \\
\hline
\end{tabular}

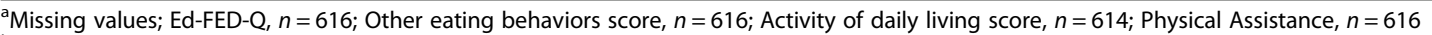

${ }^{\mathrm{b}}$ As per Mini Nutritional Assessment cut-point (MNA) [31]

physical assistance with eating, but for a few exceptions. Interestingly, NAR score for vitamin $\mathrm{C}$ was significantly higher in MTD, individuals prescribed ONS, and those requiring physical assistance with eating. Scores for vitamin D and calcium were significantly higher in participants on MTD and the NAR score for vitamin E was significantly higher in participants prescribed ONS.

Diet parameters and their association with nutrition risk (MNA-SF), malnutrition (PG-SGA) and low CC adjusted for home, unit, age and sex (simple model) are presented in Table 3. Median MAR score for the total sample was 0.80 [interquartile range $(\mathrm{IQR})=0.75,0.85$ ] and vitamins $\mathrm{D}, \mathrm{E}$, folate and calcium had the lowest median NAR values. The full models adjusted for MTD, ONS prescription, and physical assistance with eating are presented in Table 4 . In Tables 3 and 4, a positive parameter estimate $(\beta>0)$ indicates a higher MNA-SF score (i.e., better nutrition) and an odds ratio less than 1 indicates decreased risk of malnutrition (PG-SGA) and a lower likelihood of low CC. The MAR was positively associated with MNA-SF scores in both adjusted models, indicating that higher diet quality is associated with better nutrition. Likewise, a higher MAR score was associated with lower odds of malnutrition (PG-SGA), even when fully adjusted $[\mathrm{OR}=0.42 ; 95 \% \mathrm{CI}(0.31,0.58)$; Table 4], but was not associated with a lower CC in either model. The NAR scores for most nutrients (13 of the 17) had a significant positive association with MNASF score in the simple model (Table 3 ). In the fully adjusted models, ten nutrients remained significantly associated with MNA-SF score. Only one nutrient (vitamin C) had a significant negative association with MNA-SF score $[\beta=-1.37$; $95 \% \mathrm{CI}(-2.58,-0.17)]$, indicating that the higher vitamin $C$ intake, the greater the risk of malnutrition, but this association was not significant in the fully adjusted model (Table 4). Higher NAR for all but two nutrients (vitamins $\mathrm{C}$ and $\mathrm{E}$ ) were associated with a lower likelihood of being malnourished (PG-SGA) in the simple model (all OR $<1.0$ ), and only vitamin $B_{3}$ lost significance in the fully adjusted model. Examining low CC as the outcome, higher NAR scores for six of the key nutrients (folate, iron, magnesium, selenium and vitamins $B_{1}$ and $B_{3}$ ) were associated with reduced risk of low $C C$, whereas a higher vitamin E NAR $[\mathrm{OR}=1.28$; 95\% CI $(1.11,1.49)]$ was associated with a greater risk of low CC in the simple model. Only magnesium was significantly associated with low CC [OR $=0.80 ; 95 \%$ CI $(0.69,0.94)]$ in the fully adjusted model; odds of low CC were reduced when the NAR for magnesium was higher.

\section{Discussion}

This study examined diet quality of LTC residents using the MAR method and its association with malnutrition and low CC. Comparable to other studies conducted in LTC, approximately half of residents were malnourished or at risk of malnutrition according to the PG-SGA and MNA-SF [1-3]. The percentage of residents found to have low $\mathrm{CC}$ was similar to the percentage of residents at risk for malnutrition; $\mathrm{CC}$ is highly associated with 
Table 2 Food intake and diet quality by diet texture, oral nutritional supplements and assistance with eating

\begin{tabular}{|c|c|c|c|c|c|c|c|}
\hline & \multirow[t]{2}{*}{ Total Sample } & \multicolumn{2}{|c|}{$\begin{array}{l}\text { Modified Texture Diet (IDDSI 3- } \\
\text { 5) Mean (SD) }\end{array}$} & \multicolumn{2}{|c|}{$\begin{array}{l}\text { Oral Nutritional Supplements } \\
\text { Prescribed Mean (SD) }\end{array}$} & \multicolumn{2}{|c|}{$\begin{array}{l}\text { Physical Assistance with Eating } \\
\text { Sometimes/Often }{ }^{a} \text { Mean (SD) }\end{array}$} \\
\hline & & No & Yes & No & Yes & No & Yes \\
\hline Number of Residents (n) & 619 & 415 & 204 & 430 & 189 & 475 & 141 \\
\hline Energy Intake (kcal/day) & $1556.3(294.1)$ & $1578.9(274.3)$ & $1510.2(326.7)^{*}$ & $1580.3(272.6)$ & $1501.6(332.4)^{*}$ & $1583.1(276.6)$ & $1478.0(323.1)^{*}$ \\
\hline Protein intake (g/day) & $57.5(13.0)$ & $57.5(11.7)$ & $57.5(15.3)$ & $58.0(12.1)$ & $56.3(14.8)$ & $58.4(12.2)$ & $54.9(14.7)^{*}$ \\
\hline MAR & $0.79(0.09)$ & $0.80(0.08)$ & $0.78(0.10)$ & $0.79(0.07)$ & $0.78(0.11)$ & $0.80(0.07)$ & $0.77^{*}(0.11)$ \\
\hline \multicolumn{8}{|l|}{ NAR } \\
\hline Vitamin $D^{b}$ & $0.28(0.11)$ & $0.27(0.11)$ & $0.30^{*}(0.12)$ & $0.27(0.11)$ & $0.28(0.12)$ & $0.28(0.11)$ & $0.27(0.12)$ \\
\hline Vitamin E a-tocopherol & $0.34(0.13)$ & $0.34(0.13)$ & $0.34(0.14)$ & $0.31(0.09)$ & $0.40^{*}(0.19)$ & $0.34(0.13)$ & $0.35(0.14)$ \\
\hline Folate (DFE) & $0.58(0.18)$ & $0.63(0.17)$ & $0.48^{*}(0.17)$ & $0.62(0.16)$ & $0.51^{*}(0.21)$ & $0.61(0.19)$ & $0.48^{*}(0.19)$ \\
\hline Calcium & $0.61(0.19)$ & $0.60(0.18)$ & $0.64^{*}(0.20)$ & $0.61(0.18)$ & $0.62(0.20)$ & $0.62(0.19)$ & $0.60(0.19)$ \\
\hline Magnesium & $0.65(0.15)$ & $0.65(0.14)$ & $0.64(0.17)$ & $0.64(0.13)$ & $0.66(0.17)$ & $0.66(0.13)$ & $0.62^{*}(0.17)$ \\
\hline Vitamin $B_{6}$ & $0.75(0.16)$ & $0.74(0.15)$ & $0.75(0.18)$ & $0.74(0.15)$ & $0.76(0.19)$ & $0.75(0.15)$ & $0.74(0.19)$ \\
\hline Zinc & $0.81(0.16)$ & $0.80(0.16)$ & $0.82(0.18)$ & $0.80(0.15)$ & $0.82(0.18)$ & $0.82(0.15)$ & $0.79(0.18)$ \\
\hline Vitamin A (RAE) & $0.82(0.17)$ & $0.82(0.16)$ & $0.81(0.18)$ & $0.83(0.16)$ & $0.78^{*}(0.19)$ & $0.82(0.16)$ & $0.79(0.20)$ \\
\hline Vitamin C & $0.90(0.17)$ & $0.88(0.19)$ & $0.94^{*}(0.13)$ & $0.89(0.18)$ & $0.94^{*}(0.15)$ & $0.89(0.18)$ & $0.95^{*}(0.14)$ \\
\hline Copper & $0.92(0.12)$ & $0.93(0.11)$ & $0.91(0.15)$ & $0.92(0.12)$ & $0.92(0.14)$ & $0.94(0.11)$ & $0.88^{*}(0.16)$ \\
\hline Vitamin $B_{1}$ & $0.93(0.13)$ & $0.95(0.11)$ & $0.90^{*}(0.16)$ & $0.95(0.10)$ & $0.90^{*}(0.16)$ & $0.95(0.10)$ & $0.89^{*}(0.17)$ \\
\hline Selenium & $0.96(0.12)$ & $0.99(0.06)$ & $0.92^{*}(0.18)$ & $0.98(0.07)$ & $0.92^{*}(0.17)$ & $0.98(0.06)$ & $0.90^{*}(0.19)$ \\
\hline Iron & $0.97(0.09)$ & $0.98(0.07)$ & $0.95^{*}(0.12)$ & $0.97(0.08)$ & $0.95^{*}(0.11)$ & $0.98(0.06)$ & $0.94^{*}(0.12)$ \\
\hline Vitamin $B_{12}$ & $0.97(0.08)$ & $0.98(0.08)$ & $0.96(0.10)$ & $0.97(0.08)$ & $0.96(0.09)$ & $0.98(0.07)$ & $0.96^{*}(0.11)$ \\
\hline Vitamin $B_{2}$ & $0.98(0.07)$ & $0.99(0.04)$ & $0.97^{*}(0.10)$ & $0.99(0.05)$ & $0.97^{*}(0.09)$ & $0.99(0.04)$ & $0.96^{*}(0.11)$ \\
\hline Vitamin $\mathrm{B}_{3}{ }^{\mathrm{C}}$ & $0.98(0.07)$ & $0.99(0.04)$ & $0.96^{*}(0.12)$ & $0.99(0.04)$ & $0.96^{*}(0.11)$ & $0.99(0.04)$ & $0.96 *(0.12)$ \\
\hline Phosphorus & $0.98(0.06)$ & $0.99 *(0.05)$ & $0.98^{*}(0.08)$ & $0.99(0.04)$ & $0.97^{*}(0.09)$ & $0.99(0.04)$ & $0.97^{*}(0.09)$ \\
\hline
\end{tabular}

${ }^{a}$ Data missing for 3 residents, $n=616$. Food and nutrient intake stratified by modified texture diet, oral nutritional supplement use and requiring physical assistance, as these resident level covariates were a) prevalent in the sample, and b) known to be associated with malnutrition

International unit

'Niacin equivalent

${ }^{*} p<0.05$

malnutrition, as demonstrated in prior analyses of this data set [35].

Diet quality as assessed by MAR and several NARs was associated with lower risk of malnutrition when adjusting for ONS, MTD and eating assistance, confirming the importance of a nutrient dense diet in LTC facilities. As well, this association confirms that MNA-SF and PG-SGA, although focused on protein/energy malnutrition, also reflect micronutrient intake. However, no significant association was observed between MAR score and low CC and only the NAR for magnesium was significant in the fully adjusted model for low CC; protein in $\mathrm{g} / \mathrm{kg}$ body weight was of borderline significance. This suggests that factors (e.g., eating challenges), other than micronutrients and diet quality may be more influential on low muscle mass.

Previous studies have found a positive association between mealtime assistance on energy intake of residents with dementia [36, 37]. Yet, the amount of eating assistance is critical. In the main analysis for M3, it was identified that those who received eating assistance 'often', had statistically significantly higher energy intake than those who received eating assistance 'sometimes' [38]. It was concluded that when one-on-one assistance is provided, residents' needs are met, but when residents still participate in some independent eating they are at increased risk for low intake. In the current analysis, 'sometimes' and 'often' receiving eating assistance were amalgamated to provide a sufficiently large group for comparison to those who received no eating assistance. This likely explains the divergence in findings from the main analysis and that from prior research [26]. Further, as noted in prior M3 analysis, persons requiring eating assistance are commonly prescribed MTDs, which are often lower in key nutrients as compared to regular texture diets [16]. Few studies have yet to examine the influence of eating assistance on protein intake and micronutrient intake in LTC residents [38]. 
Table 3 Association of diet quality with malnutrition risk and low calf circumference (simple model)

\begin{tabular}{|c|c|c|c|c|}
\hline \multirow[b]{2}{*}{ Diet Quality Parameters } & \multirow{2}{*}{$\begin{array}{l}\text { Descriptive statistics } \\
\text { MAR/NAR }^{c}\end{array}$} & \multirow{2}{*}{$\begin{array}{l}\text { Linear Regression } \\
\text { MNA-SF }\end{array}$} & \multicolumn{2}{|l|}{ Logistic Regression a, b } \\
\hline & & & PG-SGA risk (score of $\mathrm{B} / \mathrm{C}$ ) & $C C<31$ \\
\hline & Median (IQR) & Parameter Estimate (95\% Cl) & Odds Ratio ${ }^{d}(95 \% \mathrm{Cl})$ & Odds Ratio $(95 \% \mathrm{Cl})$ \\
\hline Energy Intake (kcal/day) & $1551.8(1375.0,1742.0)$ & $0.002(0.001,0.003)^{*}$ & $0.78(0.72,0.84)^{*}$ & $0.85(0.78,0.91)^{*}$ \\
\hline Protein intake (g/day) & $56.5(49.9,65.1)$ & $0.04(0.02,0.06)^{*}$ & $0.66(0.55,0.78)^{*}$ & $0.81(0.68,0.96)^{*}$ \\
\hline MAR & $0.80(0.75,0.85)$ & $5.34(2.81,7.85)^{*}$ & $0.49(0.38,0.64)^{*}$ & $0.80(0.64,1.00)$ \\
\hline \multicolumn{5}{|l|}{ NAR } \\
\hline Calcium & $0.59(0.46,0.76)$ & $1.42(0.16,2.68)^{*}$ & $0.83(0.74,0.93)^{*}$ & $0.94(0.84,1.06)$ \\
\hline Copper & $1.00(0.88,1.00)$ & $3.55(1.69,5.42)^{*}$ & $0.68(0.57,0.82)^{*}$ & $0.88(0.75,1.03)$ \\
\hline Folate (DFE) & $0.58(0.46,0.70)$ & $4.45(3.24,5.65)^{*}$ & $0.63(0.56,0.71)^{*}$ & $0.77(0.68,0.86)^{*}$ \\
\hline Iron & $1.00(1.00,1.00)$ & $5.52(3.26,7.78)^{*}$ & $0.48(0.36,0.65)^{*}$ & $0.74(0.60,0.92)^{*}$ \\
\hline Magnesium & $0.64(0.56,0.74)$ & $2.59(1.03,4.14)^{*}$ & $0.72(0.62,0.83)^{*}$ & $0.84(0.73,0.96)^{*}$ \\
\hline Phosphorus & $1.00(1.00,1.00)$ & $7.62(4.32,10.92)^{*}$ & $0.46(0.30,0.70)^{*}$ & $0.79(0.59,1.07)$ \\
\hline Selenium & $1.00(1.00,1.00)$ & $4.88(3.13,6.62)^{*}$ & $0.46(0.34,0.62)^{*}$ & $0.73(0.61,0.87)^{*}$ \\
\hline Vitamin A (RAE) & $0.84(0.70,0.99)$ & $2.29(1.01,3.58)^{*}$ & $0.73(0.64,0.82)^{*}$ & $0.92(0.81,1.03)$ \\
\hline Vitamin $B_{1}$ & $1.00(0.92,1.00)$ & $4.22(2.55,5.89)^{*}$ & $0.59(0.49,0.71)^{*}$ & $0.76(0.66,0.89)^{*}$ \\
\hline Vitamin $B_{2}$ & $1.00(1.00,1.00)$ & $5.56(2.57,8.56)^{*}$ & $0.49(0.33,0.73)^{*}$ & $0.90(0.69,1.17)$ \\
\hline Vitamin $B_{3}{ }^{e}$ & $1.00(1.00,1.00)$ & $5.56(2.77,8.35)^{*}$ & $0.43(0.26,0.70)^{*}$ & $0.62(0.46,0.84)^{*}$ \\
\hline Vitamin $B_{6}$ & $0.75(0.63,0.87)$ & $0.86(-0.54,2.25)$ & $0.80(0.70,0.90)^{*}$ & $0.98(0.87,1.11)$ \\
\hline Vitamin $B_{12}$ & $1.00(1.00,1.00)$ & $3.18(0.75,5.62)^{*}$ & $0.64(0.50,0.82)^{*}$ & $1.06(0.84,1.32)$ \\
\hline Vitamin C & $1.00(0.87,1.00)$ & $-1.37(-2.58,-0.17)^{*}$ & $1.07(0.96,1.19)$ & $1.09(0.97,1.22)$ \\
\hline Vitamin $D^{f}$ & $0.26(0.19,0.35)$ & $0.85(-1.28,2.97)$ & $0.80(0.66,0.96)^{*}$ & $0.97(0.80,1.18)$ \\
\hline Vitamin E a-tocopherol & $0.31(0.26,0.39)$ & $-1.22(-2.88,0.44)$ & $1.12(0.97,1.30)$ & $1.28(1.11,1.49)^{*}$ \\
\hline Zinc & $0.82(0.70,0.95)$ & $2.11(0.68,3.54)^{*}$ & $0.76(0.66,0.86)^{*}$ & $0.92(0.81,1.04)$ \\
\hline
\end{tabular}

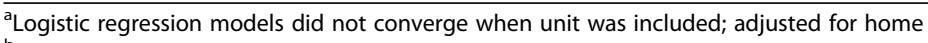

${ }^{b}$ Odds ratios calculated for: energy intake, per $100 \mathrm{kcal}$ increase; protein intake, per $10 \mathrm{~g}$ increase; energy/body weight, per $10 \mathrm{kcal} / \mathrm{kg}$ increase; protein/body weight, per $0.1 \mathrm{~g} / \mathrm{kg}$ increase; adequacy ratio (MAR/NAR) scores are per 0.1 unit increase: < 1 lowers odds of the outcome, $1=$ no association, and $>1 \mathrm{means}$ higher odds of the outcome

'Proportion consumed relative to the Recommended Dietary Allowance for a given nutrient (NAR) or average of all nutrients (MAR), to a maximum of 1.0, which indicates the Recommended Dietary Allowance was met or exceeded

${ }^{\mathrm{d}}$ Odds ratio adjusted for home, age, sex

${ }^{\mathrm{e}}$ Niacin equivalent

International unit

* $P<0.05$

As expected, results show that higher energy intake was associated with higher MNA-SF score, indicating less risk of malnutrition and with lower odds of malnutrition and low CC. One study also found that residents with malnutrition or at risk thereof had lower energy intake [39]. Likewise, protein intake was associated with all three outcome measures. This corroborates the contention that low intake and not excess metabolic demand (as is seen as well in acute care malnutrition, surgery etc.) is a primary mechanism for malnutrition in LTC residents. Investigation into why low intake occurs using a comprehensive conceptual model helped to identify these relevant factors that impair food intake in the main analysis of this study $[18,38]$.

Mean NAR score for the total sample was low for five of the 17 micronutrients: vitamin D, vitamin E, folate, calcium, and magnesium, which corresponds to previous findings that show inadequate intakes from food/beverages for these nutrients in LTC $[4,5,40]$. However, it is important to note that vitamin $\mathrm{E}$ specifically is underrepresented in nutrient analysis databases [41] due to poor reporting of this nutrient by manufacturers. The present study found that residents on MTD, on ONS or requiring physical assistance with eating were more likely to have lower intakes of nutrients than their comparators. In fact, ten of the 17 nutrients were significantly lower in residents requiring assistance with eating than those without eating assistance, nine nutrients were significantly lower in residents on ONS and eight nutrients were lower in residents on MTD. The only nutrient with a NAR higher for those requiring eating assistance was vitamin $C$. This may be due to increased use of MTD or ONS or some other covariate not modeled. Analysis to determine the percentage of residents on 
Table 4 Association of diet quality with malnutrition risk and low calf circumference (fully adjusted models)

\begin{tabular}{|c|c|c|c|}
\hline \multirow[b]{2}{*}{ Diet Quality Parameters } & \multirow{2}{*}{$\begin{array}{l}\text { Linear Regression } \\
\text { MNA-SF }\end{array}$} & \multicolumn{2}{|l|}{ Logistic Regression ${ }^{a . b}$} \\
\hline & & PG-SGA risk (score of $\mathrm{B} / \mathrm{C}$ ) & $C C<31$ \\
\hline & Parameter Estimate (95\% Cl) & Odds Ratio ${ }^{c}(95 \% \mathrm{Cl})$ & Odds Ratio (95\% Cl) \\
\hline Energy Intake (kcal/day) & $0.001(0.001,0.002)^{*}$ & $0.77(0.70,0.85)^{*}$ & $0.87(0.80,0.95)^{*}$ \\
\hline Protein intake (g/day) & $0.03(0.01,0.04)^{*}$ & $0.63(0.51,0.77)^{*}$ & $0.84(0.70,1.01)$ \\
\hline MAR & $3.58(1.35,5.82)^{*}$ & $0.42(0.31,0.58)^{*}$ & $0.86(0.66,1.11)$ \\
\hline \multicolumn{4}{|l|}{ NAR } \\
\hline Calcium & $1.83(0.75,2.91)^{*}$ & $0.74(0.64,0.84)^{*}$ & $0.90(0.80,1.02)$ \\
\hline Copper & $2.12(0.46,3.78)^{*}$ & $0.71(0.57,0.87)^{*}$ & $0.94(0.78,1.14)$ \\
\hline Folate (DFE) & $1.68(0.51,2.85)^{*}$ & $0.74(0.65,0.85)^{*}$ & $0.93(0.82,1.06)$ \\
\hline Iron & $3.06(0.92,5.20)^{*}$ & $0.53(0.38,0.74)^{*}$ & $0.85(0.67,1.09)$ \\
\hline Magnesium & $2.46(1.12,3.81)^{*}$ & $0.63(0.53,0.75)^{*}$ & $0.80(0.69,0.94)^{*}$ \\
\hline Phosphorus & $4.13(1.15,7.11)^{*}$ & $0.50(0.32,0.80)^{*}$ & $1.02(0.72,1.43)$ \\
\hline Selenium & $0.71(-0.98,2.39)$ & $0.62(0.43,0.89)^{*}$ & $0.96(0.79,1.17)$ \\
\hline Vitamin A (RAE) & $1.32(0.20,2.45)^{*}$ & $0.70(0.61,0.81)^{*}$ & $0.97(0.85,1.11)$ \\
\hline Vitamin $B_{1}$ & $1.77(0.24,3.29)^{*}$ & $0.68(0.55,0.83)^{*}$ & $0.89(0.75,1.05)$ \\
\hline Vitamin $B_{2}$ & $1.76(-0.94,4.46)$ & $0.55(0.35,0.86)^{*}$ & $1.18(0.87,1.60)$ \\
\hline Vitamin $\mathrm{B}_{3}{ }^{\mathrm{d}}$ & $0.82(-1.77,3.40)$ & $0.68(0.40,1.15)$ & $0.86(0.63,1.17)$ \\
\hline Vitamin $\mathrm{B}_{6}$ & $1.14(-0.07,2.34)$ & $0.69(0.60,0.81)^{*}$ & $0.95(0.83,1.09)$ \\
\hline Vitamin $B_{12}$ & $1.87(-0.24,3.99)$ & $0.59(0.44,0.79)^{*}$ & $1.18(0.91,1.53)$ \\
\hline Vitamin C & $0.04(-1.02,1.10)$ & $0.92(0.81,1.03)$ & $0.97(0.86,1.10)$ \\
\hline Vitamin $D^{e}$ & $2.08(0.25,3.91)^{*}$ & $0.61(0.49,0.77)^{*}$ & $0.86(0.69,1.06)$ \\
\hline Vitamin E a-tocopherol & $0.90(-0.59,2.38)$ & $0.84(0.71,1.01)$ & $1.07(0.91,1.26)$ \\
\hline Zinc & $2.16(0.92,3.39)^{*}$ & $0.65(0.55,0.76)^{*}$ & $0.88(0.76,1.01)$ \\
\hline
\end{tabular}

aLogistic regression models did not converge when unit was included; adjusted for home only

bOdds ratios calculated for: energy intake, per $100 \mathrm{kcal}$ increase; protein intake, per $10 \mathrm{~g}$ increase; energy/body weight, per $10 \mathrm{kcal} / \mathrm{kg}$ increase; protein/body weight, per $0.1 \mathrm{~g} / \mathrm{kg}$ increase; adequacy ratio (MAR/NAR) scores are per 0.1 unit increase: $<1$ being lower odds of the outcome, $1=$ no association, and $>1$ meaning higher odds of the outcome

'Odds ratios adjusted for resident level characteristics that were prevalent and known to be associated with malnutrition (MTD, ONS, requiring physical assistance) ${ }^{\mathrm{d}}$ Niacin equivalent

eInternational unit

* $P<0.05$

MTD and requiring eating assistance that are prescribed ONS should be further investigated. Those on MTD had a significantly higher NAR score for vitamin D (0.30), calcium (0.64) and vitamin $C(0.94)$ than regular texture consumers. Food fortification, especially with vitamin D and calcium, has been shown to increase intake of fortified nutrients in LTC [42-44]. A prior analysis of this dataset demonstrates that recipe standardization and enhancement in some provinces improved nutrient density for MTD and specifically for these nutrients [16]. Few nutrients were lower for ONS consumers than nonconsumers, yet vitamins $\mathrm{E}$ and $\mathrm{C}$ were higher in users than nonusers. As noted above, discrepancies in vitamin E content of food databases may explain this difference as all ONS include vitamin $\mathrm{E}$ and amounts are provided on labels.

Limitations to this work include the purposive sampling of homes, which likely do not represent all homes in Canada; therefore, generalization of the findings is cautioned. Random selection of homes was not feasible, but diversity was attained by recruiting homes with key characteristics such as culture, size, non/for profit, etc. By randomly selecting units and participants, selection bias was reduced; comparison of participants to the eligible pool in the home demonstrated that participants were representative of their home [27]. Data from this study suggests that some clinical improvements are required to prevent malnutrition and loss of muscle mass in LTC residents, such as: 1) improving nutritional intake of residents requiring texture-modified meals by the creation of nutrient dense, appealing and tasty foods to bring more pleasure to mealtimes; 2) providing quality and constant eating assistance during mealtimes to all residents who require physical support by training current LTC staff; and 3) ensuring nutrient-rich meals are provided by giving more attention to specific 
micronutrient content (i.e., vitamin D, vitamin E, calcium, folate, and magnesium) during menu planning.

\section{Conclusions}

This analysis demonstrates that when attempting to prevent or mitigate malnutrition, attention to micronutrient intake, in addition to energy and protein, is needed. In the past, Canada's Food Guide has been used to plan menus, potentially leading to inadequate micronutrient content [16]. The new Guide does not specify servings to be consumed per day and as a result the Dietary Reference Intake is recommended for menu development to avoid micronutrient deficiency [45]. Enhancement of the diet for protein and energy are relatively common practices in LTC [46], but micronutrient enhancement or fortification has been nominally studied or used in practice $[46,47]$. Development of enhanced recipes that go beyond energy and protein are needed to support improved nutritional status of residents. This study differs from previous research, which has been limited to single sites/regions/provinces, by providing a pan-Canadian understanding of diet quality and its association with LTC residents' malnutrition and low CC. Although overall diet quality using the MAR score was moderate, it was found to be associated with risk of malnutrition. Diet quality of several individual nutrients was also associated with malnutrition, while magnesium appears to be potentially relevant for $\mathrm{CC}$. This research adds to our understanding of the importance of considering and improving micronutrient intake when attempting to prevent or treat malnutrition in LTC homes. Future work should be directed to ensuring nutrient dense menus, including micronutrient-enhanced foods, to support nutrient intake and potentially prevent malnutrition in LTC residents.

\section{Abbreviations \\ CC: Calf circumference; Cl: Confidence interval; CPS: Cognitive performance scale; DFE: Dietary folate equivalent; Ed-FED-Q: Edinburgh Feeding Evaluation in Dementia Questionnaire; IDDSI: International Dysphagia Diet \\ Standardisation Initiative; IQR: Interquartile range; LTC: Long-term care; M3: Making the Most of Mealtimes; MAR: Mean adequacy ratio; MNA- SF: Mini-Nutritional Assessment-Short Form; MTD: Modified textured diets; NAR: Nutrient adequacy ratio; ONS: Oral nutritional supplement; PG- SGA: Patient-Generated Subjective Global Assessment; RAE: Retinol activity equivalents; SD: Standard deviation}

\section{Acknowledgements}

We thank the research assistants, provincial coordinators, and project manager for their significant contributions to the M3 project. We would also like to express our gratitude to the long-term care homes, staff, residents, and families who participated in the M3 study.

\section{Authors' contributions}

NC and LV wrote the first draft of the manuscript with contributions from HK. HK was the lead on the project and responsible for data collection in Ontario with NC, CL and SES responsible for data collection within their own provinces. LD was a key collaborator for different aspects of the data collection and JM was responsible for data analysis. All authors reviewed and commented on subsequent drafts of the manuscript. All authors are in agreement with the manuscript and declare that the content has not been published elsewhere.

\section{Funding}

Canadian Institutes for Health Research provided peer-reviewed funding for this study [grant numbers 201403MOP-326892-NUT-CENA-25463]. The sponsors had no role in the design and conduct of the study; in the collection, analysis, and interpretation of data; in the preparation of the manuscript; or in the review or approval of the manuscript.

\section{Availability of data and materials}

The datasets generated and/or analyzed during the current study are currently not publicly available since they are still being used by the coauthors but are available from Heather Keller on reasonable request during the current study and will be available in 2020 for use by others.

\section{Ethics approval and consent to participate}

This study was approved by the research ethics boards of the four universities affiliated with this project (University of Waterloo (ORE\#20056), University of Alberta (Pro00050002), University of Manitoba (J2014:139) and Université de Moncton (1415-022) and complies with the current laws of Canada. Informed written consent was provided by the resident or their alternate decision-maker. A statement is provided in the methods section regarding ethics approval: "This study was approved by the research ethics boards at the University of Waterloo (ORE\#20056), University of Alberta (Pro00050002), University of Manitoba (J2014:139), and Université de Moncton (1415-022) and complies with the current laws of Canada" and consent to participate: "Informed written consent was provided by the resident or their alternate decision-maker."

\section{Consent for publication}

Not applicable

\section{Competing interests}

The authors declare that they have no competing interests.

\section{Author details}

${ }^{1}$ École des sciences des aliments, de nutrition et d'études familiales, Faculté des sciences de la santé et des services communautaires, Université de Moncton, Moncton, NB E1A 3E9, Canada. ${ }^{2}$ Faculty of Agricultural \& Food Sciences, University of Manitoba, 35 Chancellor's Circle, Winnipeg, MB R3T 2N2, Canada. ${ }^{3}$ Faculty of Nursing, University of Alberta, Edmonton, AB T6G 1C9, Canada. ${ }^{4}$ Department of Food Science, University of Guelph, Guelph, Ontario N1G 2W1, Canada. ${ }^{5}$ Schlegel-University of Waterloo Research Institute for Aging, 250 Laurelwood Drive, Waterloo, ON N2J OE2, Canada. ${ }^{6}$ Applied Health Sciences, University of Waterloo, 200 University Ave W, Waterloo, ON N2L, 3G1, Canada.

Received: 29 April 2019 Accepted: 14 October 2019

Published online: 09 December 2019

\section{References}

1. López-Contreras MJ, Torralba C, Zamora S, Pérez-Llamas F. Nutrition and prevalence of undernutrition assessed by different diagnostic criteria in nursing homes for elderly people. J Hum Nutr Diet. 2012;25(3):239-46.

2. Boström AM, Van Soest D, Kolewaski B, Milke DL, Estabrooks CA. Nutrition status among residents living in a veterans' long-term facility in Western Canada: a pilot study. J Am Med Dir Assoc. 2011;12(3):217-25.

3. Bell CL, Tamura BK, Masaki KH, Amella EJ. Prevalence and measures of nutritional compromise among nursing home patients: weight loss, low body mass index, malnutrition, and feeding dependency. A systematic review of the literature. J Am Med Dir Assoc. 2013;14:94-100.

4. Wendland BE, Greenwood CE, Weinberg I, Young KWH. Malnutrition in institutionalized seniors: the iatrogenic component. J Am Geriatr Soc. 2003; 51:85-90

5. Parrott MD, Young KWH, Greenwood CE. Energy-containing nutritional supplements can affect usual energy intake post supplementation in institutionalized seniors with probable Alzheimer's disease. J Am Geriatr Soc 2006;54:1382-7.

6. Greenwood CE, Tam C, Chan M, Young KWH, Binns MA, van Reekum R. Behavioral disturbances, not cognitive deterioration, are associated with 
altered food selection in seniors with Alzheimer's disease. J Geront Med Sci. 2005;60A(4):499-505.

7. Lengyel CO, Whiting SJ, Zello GA. Nutrient inadequacies among elderly residents of long-term care facilities. Can J Diet Pract Res. 2008;69(2):82-8.

8. Mesquita AF, da Silva EC, Eickemberg M. Carneiro Roriz Jairza AK, BarretoMedeiros M, Barbosa Ramos L. factors associated with sarcopenia in institutionalized elderly. Nutr Hosp. 2017;34(2):345-51.

9. Kawakami R, Murakami H, Sanada K, Tanaka N, Sawada SS, Tabata I, et al. Calf circumference as a surrogate marker of muscle mass for diagnosing sarcopenia in Japanese men and women. Geriatr Gerontol Int. 2015;15:969-76.

10. Rolland $Y$, Lauwers-Cances $V$, Cournot M, Nourhashémi F, Reynish W, Rivière D, et al. Sarcopenia, calf circumference, and physical function of elderly women: a cross-sectional study. J Am Geriatr Soc. 2003;51:1120-4.

11. Landi F, Onder G, Russo A, Liperoti R, Tosato M, Martone AM, et al. Calf circumference, frailty and physical performance among older adults living in the community. Clin Nutr. 2014;33:539-44.

12. Liu G, Lu L, Sun Q, Ye X, Sun L, Liu X, et al. Poor vitamin D status is prospectively associated with greater muscle mass loss in middle-aged and elderly Chinese individuals. J Acad Nutr Diet. 2014 Oct;114(10):1544-51.

13. Park S, Ham JO, Lee BK. A positive association of vitamin D deficiency and sarcopenia in 50 year old women, but not men. Clin Nutr. 2014;33:900-5.

14. Dupuy C, Lauwers-Cances V, van Kan GA, Gillette S, Schott AM, Beauchet O, et al. Dietary vitamin D intake and muscle mass in older women. Results from a cross-sectional analysis of the EPIDOS study. J Nutr Health Aging. 2013;17(2):119-24

15. Mastaglia SR, Seijo M, Muzio D, Somoza J, Nuñez M, Oliveri B. Effect of vitamin D nutritional status on muscle function and strength in healthy women aged over sixty-five years. J Nutr Health Aging. 2011;15(5):349-54.

16. Vucea V, Keller HH, Morrison JM, Duncan AM, Duizer LM, Carrier N, et al. Nutritional quality of regular and pureed menus in Canadian long term care homes: an analysis of the making the Most of mealtimes (M3) project. BMC Nutr. 2017. https://doi.org/10.1186/s40795-017-0198-3.

17. Dahl WJ, Whiting SJ, Tyler RT. Protein content of pureed diets: implications for planning. Can J Diet Pract Res. 2007;68:99-102.

18. Keller H, Carrier N, Duizer L, Lengyel C, Slaughter S, Steele C. Making the most of mealtimes (M3): grounding mealtime interventions with a conceptual model. J Am Med Dir Assoc. 2014;15:158-61.

19. Abdelhamid A, Bunn D, Copley M, Cowap V, Dickinson A, Gray L, et al. Effectiveness of interventions to directly support food and drink intake in people with dementia: systematic review and meta-analysis. BMC Geriatr. 2016. https://doi.org/10.1186/s12877-016-0196-3.

20. Lee KM, Song JA. Factors influencing the degree of eating ability among people with Dementia. J Clin Nurs. 2015;24:1707-17.

21. Chang CC, Roberts BL. Malnutrition and feeding difficulty in Taiwanese older with dementia. J Clin Nurs. 2011;20:2153-61.

22. Chang CC, Roberts BL. Feeding difficulty in older adults with dementia. J Clin Nurs. 2008;17:2266-74

23. Lin LC, Watson R, Lee YC, Chou YC, Wu SC. Edinburgh feeding evaluation in dementia (EdFED) scale: cross-cultural validation of the Chinese version. J Adv Nurs. 2008;62:116-23.

24. Cawood AL, Elia M, Stratton RJ. Systematic review and meta-analysis of the effects of high protein oral nutritional supplements. Ageing Res Rev. 2012;11(2):278-96.

25. Simmons SF, Zhu X, Keller E. Cost-effectiveness of nutrition interventions in nursing home residents: a pilot intervention. J Nutr Health Aging. 2010; 14(5):367-72.

26. Keller HH, Lengyel C, Carrier N, Slaughter SE, Morrison J, Duncan AM, et al. Prevalence of inadequate micronutrient intakes of Canadian long-term care residents. BJN. 2018;119(9):1047-56.

27. Keller HH, Carrier N, Slaughter S, Lengyel C, Steele CM, Duizer L, et al. Making the Most of mealtimes (M3): protocol of a multi-Centre cross-sectional study of food intake and its determinants in older adults living in long term care homes. BMC Geriatr. 2017. https://doi.org/10.1186/s12877-016-0401-4.

28. Cichero JA, Lam P, Steele CM, Hanson B, Chen J, Dantas RO, et al. Development of international terminology and definitions for texturemodified foods and thickened fluids used in dysphagia management: the IDDSI framework. Dysphagia. 2016;2:1-22.

29. Hirdes JP, Ljunggren G, Morris JN, Frijters DHM, Soveri HF, Gray L, et al. Reliability of the interRAl suite of assessment instruments: a 12 -country study of an integrated health information system. BMC Health Serv Res. 2008. https://doi.org/10.1186/1472-6963-8-277.
30. Isenring EA, Banks M, Ferguson M, Bauer JD. Beyond malnutrition screening: appropriate methods to guide nutrition care for aged care residents. J Acad Nutr Diet. 2012 Mar;112(3):376-81.

31. Guigoz $Y$. The mini-nutritional assessment $\left(M N A^{\circledast}\right)$ review of the literature what does it tell us? J Nutr Health Aging. 2006;10:466-87.

32. Bauer J, Capra S, Ferguson M. Use of the scored patient-generated subjective global assessment (PG-SGA) as a nutrition assessment tool in patients with cancer. Eur J Clin Nutr. 2002;56:779-85.

33. Watson R, Deary IJ. Feeding difficulty in elderly patients with dementia: confirmatory factor analysis. Int J Nurs Stud. 1997;34(6):405-14.

34. Kant AK. Indexes of overall diet quality: a review. J Am Diet Assoc. 1996;96:785-91.

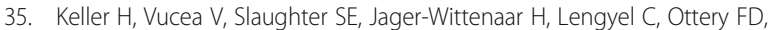
Carrier N. Prevalence of malnutrition or risk in residents in long term care: comparison of four tools. J Nutr Gerontol Geriatr. 2019:1-17.

36. Simmons SF, Keeler E, Zhuo X, Hickey KA, Sato HW, Schnelle JF. Prevention of unintentional weight loss in nursing home residents: a controlled trial of feeding assistance. J Am Geriatr Soc. 2008;56:1466-73.

37. Wong A, Burford S, Wyles CL, Mundy H, Sainsbury R. Evaluation of strategies to improve nutrition in people with dementia in an assessment unit. J Nutr Health Aging. 2008;12:309-12.

38. Keller HH, Carrier N, Slaughter SE, Lengyel C, Steele CM, Duizer L, et al. Prevalence and determinants of poor food intake of residents living in longterm care. J Am Med Dir Assoc. 2017;18(11):941-7.

39. Strathmann S, Lesser S, Bai-Habelski J, Overzier S, Paker-Eichelkraut HS, Stehle $P$, et al. Institutional factors associated with the nutritional status of residents from 10 German nursing homes (ERNSTES study). J Nutr Health Aging. 2013;17(3):271-6.

40. Lammes E, Törner A, Akner G. Nutrient density and variation in nutrient intake with changing energy intake in multimorbid nursing home residents. J Hum Nutr Diet. 2009;22:210-8.

41. Klurfeld DM. Use of DRIs in Federal Nutrition Programs. USDA Agricultural Research Service 2017. www.nationalacademies.org/hmd/ /media/Files/ Activity\%20Files/Nutrition/Framework\%20DRI/10_Klurfeld-Use\%20of\%2 0DRIs\%20in\%20Federal\%20Nutrition\%20Programs-Jan\%202017.pdf

42. Bonjour JP, Benoit V, Payen F, Kraenzlin M. Consumption of yogurts fortified in vitamin $\mathrm{D}$ and calcium reduces serum parathyroid hormone and markers of bone resorption: a double-blind randomized controlled trial in institutionalized elderly women. J Clin Endocrinol Metab. 2013;98:e2915-21.

43. Mocanu V, Stitt PA, Costan AR, Voroniuc O, Zbranca E, Luca V, et al. Long-term effects of giving nursing home residents bread fortified with 125 microg (5000 IU) vitamin D3 per daily serving. Am J Clin Nutr. 2009:89:1132-7.

44. Adolphe JL, Whiting SJ, Dahl WJ. Vitamin fortification of puréed foods for long term care residents. Can J Diet Pract Res. 2009;70:143-50.

45. Ontario Long Term Care Action Group. Best practices for nutrition, food service and dining in long term care homes. 2019. https://www.dietitians. ca/Downloads/Public/Dietitians\%2D\%2DViews/2019-Dietitians-of-CanadaBest-Practices-for-Nutri.aspx

46. Lam IT, Keller HH, Duizer L, Stark K. Micronutrients on the menu: enhancing the quality of food in long-term Care for Regular, nontherapeutic menus. Can J Diet Pract Res. 2015;76:1-7.

47. Lam IT, Keller HH, Pfisterer K, Duizer L, Stark K, Duncan AM. Micronutrient food fortification for residential care: a scoping review of current interventions. J Am Med Dir Assoc. 2016:17(7):588-95.

\section{Publisher's Note}

Springer Nature remains neutral with regard to jurisdictional claims in published maps and institutional affiliations. 